\title{
¿HACIA DÓNDE SE ENCAMINA LA TRANSICIÓN BIRMANA?
}

\section{Emilio De Miguel Calabria ${ }^{1}$ \\ Diplomático}

\section{Resumen:}

El objeto de este artículo es considerar si, una vez concluída la hoja de ruta de siete pasos, elaborada la Constitución de 2008 y celebradas las elecciones de noviembre de 2010, podemos considerar que Birmania ha iniciado efectivamente una transición hacia un régimen civil y razonablemente democrático o si todo el proceso no ha sido más que un ejercicio de maquillaje y relaciones públicas.

Palabras clave: Birmania, transición democrátca.

\section{Abstract:}

The objective of this paper is to consider if Burma has effectively initiated the transition towards a reasonable democratic civil regime or if the process has been nothing more than smoke screen and public relations campaign. This will be more evident once the seven steps designed in the roadmap put in place by the 2008 Constitution and celebrated in the 2010 elections are completed

Keywords: Burma, democratic transition.

Copyright C UNISCI, 2011.

The views expressed in these articles are those of the authors, and do not necessarily reflect the views of UNISCI. Las opiniones expresadas en estos artículos son propias de sus autores, y no reflejan necesariamente la opinión de UNISCI.

\footnotetext{
1 Emilio de Miguel Calabria ocupa la segunda Jefatura de la Embajada española en Singapore. Email: emilio.demiguel@maec.es
} 


\section{Introducción}

El objeto de este artículo es considerar si, una vez concluída la hoja de ruta de siete pasos, elaborada la Constitución de 2008 y celebradas las elecciones de noviembre de 2010, podemos considerar que Birmania ha iniciado efectivamente una transición hacia un régimen civil y razonablemente democrático o si todo el proceso no ha sido más que un ejercicio de maquillaje y relaciones públicas.

\section{Khin Nyunt y la hoja de ruta de siete pasos}

El 30 de agosto de 2003 el entonces Primer Ministro birmano, el General Khin Nyunt, anunció una hoja de ruta de siete pasos para la transición a una democracia disciplinada. Los siete pasos eran: 1) Convocatoria de la Convención Nacional, que estaba suspendida desde 1996; 2) Tras la convocatoria de la Convención la puesta en marcha paso a paso del proceso necesario para la emergencia de un sistema democrático disciplinado y genuino; 3) Elaboración de una nueva Constitución, conforme a los principios que haya establecido la Convención Nacional; 4) Referéndum para aprobar la nueva Constitución; 5) Celebración de elecciones a los cuerpos legislativos; 6) Constitución de los cuerpos legislativos; 7) Construcción de una nación democrática, moderna y desarrollada por los líderes elegidos y por el Gobierno. ${ }^{2}$ La reacción más generalizada al anuncio, sobre todo en los medios occidentales y entre la oposición birmana, fue de escepticismo. No obstante, hubo quienes estimaron que tal vez la hoja de ruta anunciada ofreciera potencial real para el inicio de una transición democrática. Esta fue, entre otros, la opinión del Secretario General de NNUU Kofi Anan, quien estimó que la hoja de ruta tenía el potencial para generar cambios positivos ${ }^{3}$. El entonces Relator Especial de NNUU sobre la situación de los Derechos Humanos en Myanmar, Paulo-Sergio Pinheiro, ha contado cómo incluso los más escépticos dentro del sistema de NNUU debieron plegarse al optimismo allí reinante: "He de confesar que desde el anuncio de la hoja de ruta de siete pasos en 2003 me mostré muy escéptico sobre ella y mis informes de ese periodo revelaban mi estado de ánimo de forma velada, para no tirar al bebé con el agua sucia tan pronto. La fórmula que decidí utilizar fue que la hoja de ruta de siete pasos podía ser el vehículo para una transición democrática al menos hasta el golpe contra Khin Nyunt. No quise contradecir a la comunidad internacional y a las NNUU que siguieron considerando que la hoja de ruta tenía algún valor para conseguir algo positivo en el país. Pero con eso, le atribuímos algo que la hoja de ruta no podía conseguir: la transición al constitucionalismo civil democrático." "El Profesor Pinheiro hace una distinción muy adecuada, que no conviene que perdamos de vista: una cosa son las intenciones que tenía el Primer Ministro Khin Nyunt en 2003 cuando presentó por primera vez la hoja de ruta, y otra cómo la hoja de ruta se ha realizado con Khin Nyunt fuera del poder.

Para entender cómo se llegó a la hoja de ruta, resulta instructivo hacer una pequeña cronología de los acontecimientos que la precedieron:

\footnotetext{
${ }^{2}$ Para ver la justificación de los siete puntos desde el punto de vista del régimen birmano puede consultarse la presentación que realizó el 27 de enero de 2004 el Vice-Ministro para Asuntos Exteriores de Birmania U Khin Maung Win en el Myanmar Institute of Strategic and International Studies.

3 "Yearbook of the United Nations 2005"

4 "The Myanmar's Road Map to the consolidation of military authoritarianism" por Paulo-Sergio Pinheiro, presentación en el seminario “Asia-Pacific Security Challenges”, Praga 7-9 de septiembre de 2008.
} 
- 4 de marzo de 2002: Se revela que uno de los yernos del ex-dictador Ne Win, Aye Zaw Win, había conspirado para derribar a la junta militar. Aye Zaw Win, el propio $\mathrm{Ne}$ Win y miembros de su entorno son puestos bajo arresto domiciliario. ${ }^{5}$ Fue un episodio oscuro que probablemente tuviera más que ver con rivalidades empresariales entre el clan de Ne Win y los generales en el poder.

- 6 de mayo de 2002: Aung San Suu Kyi es liberada tras haber pasado 19 meses sometida a arresto domiciliario.

- 5 de diciembre de 2002: Muere el ex-dictador Ne Win, que llevaba desde marzo sometido a arresto domiciliario. Aunque desde finales de los noventa su influencia política había sido mínima, es de resaltar que no se le ofreció un funeral de estado y que sus ritos funerales quedaron reducidos al círculo más íntimo.

- 30 de mayo de 2003: Masacre de Depayin. El convoy en el que viajaba Aung San Suu Kyi es atacado por agentes instigados por el Gobierno. Se producen decenas de muertos. Tras la masacre Aung San Suu Kyi es detenida por el Gobierno y vuelve a sufrir arresto domiciliario.

- 16-17 de junio de 2003: Cumbre Ministerial de ASEAN, cuyo comunicado final hizo mención al incidente de Depayin, ${ }^{6}$ algo poco habitual dada la reticencia de los países miembros a deliberar sobre los asuntos internos de sus socios. Un mes después de la Cumbre, Birmania liberó a 91 presos políticos.

- 25 de agosto de 2003: Khin Nyunt, el jefe de la inteligencia militar fue designado Primer Ministro. Dentro del régimen Khin Nyunt estaba considerado como un moderado. Habiendo estado más expuesto al exterior, era más sensible a la opinión internacional.

- 30 de agosto de 2003: Khin Nyunt anuncia la hoja de ruta de siete pasos.

Las lecturas sobre el significado del ascenso de Khin Nyunt y su hoja de ruta fueron muy diversas, yendo desde el escepticismo más radical hasta un cauto optimismo. Un punto que esas lecturas tuvieron en común fue que los cambios habían sido provocados por la dura reacción internacional a la matanza de Depayin. ${ }^{7}$ Dado el secretismo del régimen, más compleja fue la interpretación que debía darse al nombramiento de Khin Nyunt como Primer Ministro. El periodista especializado en Birmania Bertil Lintner resumió el desconcierto de los analistas en el artículo "The military digs in for the long haul" que publicó "The Far Eastern Economic Review el 25 de septiembre de 2003:

\footnotetext{
5 "Ne Win's legacy: Burma in shambles" por Richard S. Ehrlich, "The Washington Times", 21-12-2002.

${ }^{6}$ El texto del Comunicado dijo textualmente: "Hemos debatido los recientes acontecimientos políticos en Myanmar, especialmente el incidente del 30 de mayo de 2003. Hemos tomado nota de los esfuerzos del Gobierno de Miyanmar por promover la paz y el desarrollo. A este respecto, instamos a Myanmar a que retome los esfuerzos por la reconciliación nacional y el diálogo entre todas las partes concernidas, conducentes a una transición pacífica a la democracia. Damos la bienvenida a las garantías dadas por Myanmar de que las medidas adoptadas tras el incidente son temporales y deseamos un pronto levantamiento de las restricciones a Daw Aun San Suu Kyi y a los miembros de la LND..."

${ }^{7}$ A título de ejemplo, el International Crisis Group en su informe de abril de 2004 señaló: “...la reestructuración del Gobierno y la "hoja de ruta" de siete pasos para la reforma constitucional y política que fueron anunciadas el pasado agosto como respuesta al rechazo internacional a los acontecimientos del 30 de mayo de 2003..."
} 
“¿Fue un ascenso, una descenso de rango o simplemente más es más humo y espejos? Más de tres semanas después de que el General Khin Nyunt hubiera sido nombrado Primer Ministro de Birmania el 27 de agosto [sic], los analistas están todavía intentando adivinar el significado del movimiento. Los proponentes de la teoría del ascenso dicen que Khin Nyunt es más pragmático que sus conmilitones y que es más probable que Birmania progrese con él a cargo de los asuntos cotidianos. Señalan su "hoja de ruta" a la democracia del 30 de agosto como evidencia de su acercamiento más iluminado.

Aquellos que piensan que fue degradado dicen que el puesto de Primer Ministro es en Buena medida un puesto ceremonial y que por tanto Khin Nyunt ha sido marginado. Pero la explicación más probable para el cambio, según los diplomáticos, es que se trató de una simple rotación de funciones. Añaden asimismo que los oficiales gobernantes de Birmania deben haber actuado bajo la creencia de que Khin Nyunt es visto como más aceptable por el mundo exterior que el principal lider del pais- el General Than Shwe.",

De alguna manera hay una correlación entre el significado a dar a la hoja de ruta y el hecho de que la designación de Khin Nyunt como Primer Ministro fuera una degradación o un ascenso. En el primero de los casos, tendríamos que todo habría sido un ejercicio de relaciones públicas del régimen militar tras la masacre de Depayin. En el segundo tendríamos el ascenso del sector más moderado del régimen militar y la puesta en marcha con muchas cautelas de un camino hacia la transición democrática. ${ }^{9}$ En todo caso, la cuestión ya es un poco ociosa toda vez que en octubre de 2004 Khin Nyunt fue depuesto y arrestado y el núcleo duro de la junta militar reasumió el control del poder. ${ }^{10}$ Resulta interesante advertir que, a pesar del derrocamiento de Khin Nyunt, el General Than Swhe y su nuevo Primer Ministro Soe Win continuaron con la hoja de ruta. El hecho de que la hoja de ruta sobreviviese a su creador implicaría dos cosas: 1) Su establecimiento debió de haber sido acordado por el régimen en pleno, y no sólo por Khin Nyunt, de acuerdo con la tendencia del régimen militar birmano a buscar el consenso en la cúpula; 2) En consonancia con el punto anterior, cabe inferir que el componente de "maquillaje" del régimen de cara al exterior debió de estar presente desde el primer momento. Si además de la operación de relaciones públicas, la hoja de ruta aspiraba a ser la herramienta para una transición, es algo que ya estamos en situación de discernir, ahora que hemos llegado al séptimo de los pasos previstos. Para valorar la sinceridad de la hoja de ruta y adivinar hacia dónde se dirige Birmania, hay tres elementos clave: 1) La Constitución; 2) La legislación electoral y sobre partidos políticos; 3) La constitución de las instituciones tras las elecciones de noviembre de 2010. En su análisis no me detendré en las vicisitudes históricas de cómo se produjeron, sino en los resultados finales.

\footnotetext{
${ }^{8}$ Como puede apreciarse por la última frase, también Bertil Lintner se apunta a la tesis de que el motor de los cambios fue la reacción del exterior.

${ }^{9}$ En este sentido iban las reflexiones que se hacía Josef Silverstein en "Moving in two directions: where is Burma headed?", Legal Issues on Burma Journal, Un. 17, Abril de 2004.

${ }^{10}$ En diciembre de 2007 realicé una visita de trabajo a Birmania y la opinion generalizada de mis comunicantes (miembros de la comunidad diplomática y del sistema de NNUU) era que Than Shwe y su entorno nunca dejaron realmente las riendas del poder, aunque Khin Nyunt hubiera podido pensar que le habían otorgado más poder que el que realmente le habían dado. Khin Nyunt era visto por la cúpula del régimen como un "outsider" y despertaba recelos su control de aparato de inteligencia. Un indicio de la fragilidad de su control es la rapidez con la que Than Shwe desmontó sus redes de inteligencia en octubre de 2004.
} 


\section{La Constitución de 2008}

La Constitución otorga desde sus primeros artículos un papel dirigente al Ejército. El Capítulo 1 establece que uno de los seis principios básicos es "capacitar a los Servicios de Defensa para que puedan participar en el papel de liderazgo político nacional del Estado." El art. 20 dice que las FFAA serán responsables de "la no desintegración de la Unión", la no desintegración de la solidaridad nacional y la perpetuación de la soberanía" así como de la salvaguardia de la Constitución.

Estos principios genéricos se concretan en: 1) Presencia de representantes militares, designados por el Comandante en Jefe, en las asambleas legislativas nacional y regionales y en el Ejecutivo (art.14, art.109, art. 232); 2) Autonomía absoluta del Ejército en sus áreas de actuación ${ }^{12}$; 3) El Comandante en Jefe de las FFAA asumirá el poder si se declara el estado de emergencia a nivel nacional (art.40, art. 413 b) ${ }^{13}$ y art. 419); 4) Facultades de supervisión y/o control sobre otros poderes del Estado ${ }^{14}$; 5) Jurisdicción propia (arts. 291, 292, 319 y $343^{15}$ ); 6) Control de facto sobre cualquier intento de enmendar la Constitución, ya que el art.436 introduce unas mayorías parlamentarias tales para enmendar la Constitución, que son inobtenibles sin el concurso de algunos de los diputados designados por las FFAA.

El juicio formulado por los distintos observadores sobre la Constitución de 2008 es casi sin excepción negativo. Susanne Prager Nyein la ha tachado de "cubierta decorativa que

\footnotetext{
${ }^{11}$ Uno de los argumentos utilizados para asentar la legitimidad de su poder durante el régimen de Newin (19621988) fue precisamente su papel como mantenedoras de la unidad nacional y su lucha contra las guerrillas secesioniastas étnicas. Ver "Legitimacy under Military regime: Burma” por Stephen McCarthy, Politics \& Policy Vol. 38, Junio de 2010.

${ }^{12}$ Por ejemplo, el art.17 b) establece que "En los ejecutivos de la Unión, las regiones, los estados, el territorio de la Unión, las zonas autónomas y los distritos, se incluirá al personal de los Servicios de Defensa, nombrado por el Comandante en Jefe de los Servicios de Defensa para asumir las responsabilidades de la defensa, la seguridad, la administración de fronteras, etc." Es decir, no se deja al Poder Ejecutivo la facultad de designar al personal de Defensa. El art. 20 b) dice: "Los Servicios de defensa tienen el derecho de administrar y decidir independientemente todos los asuntos de las Fuerzas Armadas." El art.115 señala, por ejemplo, que cuando se forme una comisión parlamentaria para estudiar cuestiones de defensa y seguridad, se forme con los miembros de las FFAA designados como parlamentarios. El art. 208 otorga al Presidente la posibilidad de designar y cesar a los jefes de los cuerpos de los servicios civiles; significativamente no menciona a los militares.

${ }^{13}$ Para apreciar la amplitud de los poderes otorgados al Comandante en Jefe de los Servicios de Defensa, merece la pena transcribir el punto b) del artículo: "El Presidente puede, si es necesario, promulgar una orden administrativa militar. En dicha orden los poderes y responsabilidades ejecutivos y los poderes y responsabilidades judiciales relativos a la paz y la tranquilidad de la comunidad y al mantenimiento de la ley y el orden serán atribuidos al Comandante en Jefe de los Servicios de Defensa. El Comandante en Jefe puede ejercer dichos poderes y responsabilidades por sí o facultar a una autoridad militar adecuada para que los ejerza." El art. 419 va aún más lejos y señala que en tales casos se transfiere el poder soberano al Comandante en Jefe y éste "tendrá derecho a ejercer los poderes legislativo, ejecutivo y judicial." Asimismo el art. 420 le autoriza a suspender los derechos de los ciudadanos mientras dure el estado de emergencia.

${ }^{14}$ Por ejemplo, el art. 60 establece que el Presidente de la Unión sera elegido por un Colegio Electoral compuesto por tres grupos de electores. Uno de esos grupos será designado por el Comandante en Jefe de entre los miembros de las FFAA designados como parlamentarios en el Parlamento nacional o en los parlamentos regionales y estatales.

Más interesante aún es la institución del Consejo de Defensa y Seguridad Nacionales (art.201). El Presidente debe "coordinarse" con él en casos tales como la ruptura urgente de relaciones diplomáticas con un tercer país, la adopción de medidas militares en caso de agresión contra la Unión o la declaración del estado de emergencia. La Constitución no deja claro qué interpretación debe darse a esa "coordinación."

El Presidente deberá escoger a los Ministros de Defensa, Interior y Asuntos Fronterizos de entre una lista de personal apropiado que le proporcione el Comandante en Jefe (art.232).

${ }_{15}$ Este artículo señala que la decisión del Comandante en Jefe de los Servicios de Defensa es "final y concluyente" en materia de administración de la Justicia militar.
} 
codificará el predominio del Ejército dentro de un sistema político "civilizado" comparable a la Constitución de 1974" "16. El Burma Lawyers' Council considera que no es más que un intento de preservar la hegemonía militar en el país bajo el manto de un marco institucional y unas elecciones fraudulentas ${ }^{17}$. El ex-Relator Especial para los Derechos Humanos en Birmania, Paulo-Sergio Pinheiro, la ha tildado de "ardid" para "afianzar" la dictadura militar birmana $^{18}$. En sentido similar se pronuncia el Representante Especial del Secretario General de NNUU para los Derechos Humanos en Camboya, Yash Ghai, quien considera que la razón de ser primordial de la Constitución es "perpetuar el predominio del Ejército."

El breve repaso que hice anteriormente de la Constitución permite ver que esas opiniones son acertadas. La Constitución de 2008 otorga a las FFAA un papel de garantes y supervisoras del sistema que las coloca de hecho por encima de la Constitución. La impresión de que la Constitución sólo busca transformar el sistema para que todo siga igual se ve corroborada cuando examinamos la legislación relativa a los partidos políticos y al proceso electoral.

La Constitución dedica su Capítulo X a los partidos políticos. Los artículos 404 y 405 circunscriben el marco al que se debe restringir la ideología de los partidos: 1) Tener entre sus objetivos el mantenimiento de la Unión, de la solidaridad nacional y la preservación de la soberanía; 2) Ser leales al Estado; 3) Aceptar un sistema democrático multipartidista y disciplinado. En principio estos artículos no son excepcionales. La Constitución española en su artículo 6 también obliga a los partidos políticos a respetar la Constitución y las leyes.

El artículo 407 señala las circunstancias en las que se puede disolver gubernativamente un partido político: 1) Que tenga contactos con grupos insurgentes en rebelión contra la Unión ${ }^{19}$; 2) Que tenga contactos con grupos terroristas; 3) Que reciba ayuda de gobiernos extranjeros, asociaciones religiosas u otras asociaciones y personas extranjeras; 4) Que use la religión con fines políticos; 5) Que sea declarado asociación ilegal conforme a la Ley. El punto 3) introduce un hándicap importante para los nacientes partidos de oposición al privarles de una fuente clave de apoyo, el extranjero. El punto 4), cuyo tenor puede ser tan amplio como se quiera, posiblemente este pensado para evitar algún tipo de colusión entre la Sangha budista y la oposición ${ }^{20}$. El punto 5) es un peligroso cajón de sastre que queda abierto a cualquier arbitrariedad.

\section{La legislación electoral y las elecciones de noviembre de 2010}

En marzo de 2010 se promulgaron las leyes que regirían las elecciones previstas para antes de final de año. Las leyes fueron cinco: 1) La Ley de la Comisión Electoral de la Unión; 2) La

\footnotetext{
16 "Expanding Military, Shrinking Citizenry and the New Constitution in Burma" por Susanne Prager Nyein, Journal of Contemporary Asia, Noviembre de 2009.

${ }^{17}$ Ver el núm. 30 (agosto de 2008) de "LawKa PaLa- Legal Journal on Burma” que publica el Burma Lawyers' Council.

18 “The Myanmar's Road Map to the consolidation of military authoritarianism” por Paulo-Sergio Pinheiro, presentación en el seminario “Asia-Pacific Security Challenges”, Praga 7-9 de septiembre de 2008

${ }_{19}$ Este supuesto emana claramente de la conflictiva Historia que han conocido las relaciones entre el Estado central y las minorías étnicas de la periferia desde su independencia.

${ }^{20}$ Recuérdese el papel clave que jugó la Sangha en las manifestaciones de septiembre de 2007. Asimismo cabe reseñar que la costumbre de que los monjes vayan cada mañana por los hogares pidiendo limosna, hace de ellos unos propagandistas políticos en potencia. A esas dos consideraciones, relacionadas con la religión budista, cabría añadir otra: alejar el peligro de que la minoría musulmana se organice en un partido político confesional.
} 
Ley sobre el Registro de Partidos Políticos; 3) La Ley para las Elecciones al Parlamento Nacional; 4) La Ley para las Elecciones a la Cámara Alta; 5) La Ley para las Elecciones a los Parlamentos Regionales/Estatales.

Siguiendo la tónica establecida por la Constitución, las leyes aprobadas en marzo de 2010 introdujeron importantes restricciones al normal funcionamiento de los partidos políticos. En primer lugar, están las restricciones a la membresía. Las siguientes categorías de personas tienen vedado el ingreso o la permanencia como miembros de un partido político ${ }^{21}$ : 1) Los presos que hayan sido sentenciados ${ }^{22}$; 2) Los religiosos de cualquier religión no pueden pertenecer a partidos políticos ni $\operatorname{votar}^{23}$; 3) Los funcionarios; 4) Los ciudadanos extranjeros; 5) Quienes pertenezcan a grupos que luchen contra la Unión, a grupos terroristas y a grupos declarados ilegales ${ }^{24}$. A lo anterior hay que añadir que las leyes no prevén la posibilidad de que los birmanos del exterior puedan votar. No todas las legislaciones permiten el voto de los ciudadanos residentes en el extranjero. En el caso birmano cabe pensar que detrás de esta prohibición hay un designio político, toda vez que lo más probable es que estos emigrantes votasen contra el régimen. La inmigración, según estimaciones de la Organización Internacional de las Migraciones, afecta al 4\% de los 56 millones de habitantes del país ${ }^{25}$ Los motores de la inmigración son la persecución política y la pobreza.

El art. 6 de la Ley obliga a los partidos a asumir una serie de compromisos de carácter ideológico y operativo. Algunos de los compromisos se limitan a recoger los ya establecidos en los arts. 404 y 405 de la Constitución. Otros van más allá. Por ejemplo, el punto 4 obliga a los partidos a comprometerse a no producir escritos ni dar discursos que alienten los sentimientos religiosos y étnicos, de manera que puedan crear disturbios y que puedan tener un impacto sobre la dignidad y la moral. El punto 6 del artículo detalla con precisión la prohibición contenida en la Constitución de que reciban ayuda de asociaciones extranjeras o grupos religiosos: dicha prohibición se extiende al uso de dinero, terrenos, edificios, vehículos y bienes.

En opinión del analista Richard Horsey, la Ley sobre el Registro de Partidos Políticos de 2010 es "sustancialmente más restrictiva" que la de $1988^{26}$. El juicio de Benjamin Zawacki, un experto sobre Birmania de Amnistía Internacional, es más duro todavía: "Las disposiciones de estas leyes están en clara violación de los principios y estándares de derechos humanos, y cuando se ven en su conjunto, atacan claramente las tres libertades de

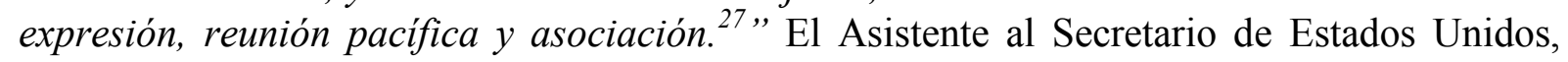

\footnotetext{
${ }^{21}$ Art. 4 de la Ley sobre el Registro de los Partidos Políticos.

${ }^{22}$ Amnistía Internacional estima en 2.200 el número de presos políticos en el país, presos que se han visto privados de participar en el proceso político.

${ }^{23}$ Esta disposición se corresponde con la práctica habitual en Birmania. No obstante, otros países budistas theravadas vecinos no siguen una práctica tan restrictiva. La legislación thailandesa no impide a los monjes ser miembros de partidos políticos ni les prohíbe votar. Igualmente, la legislación camboyana les permite pertenecer a partidos políticos y votar, aunque les prohíbe realizar actividades políticas.

${ }^{24}$ En virtud de esta disposición se priva de la posibilidad de pertenecer a un partido político, por ejemplo a los miembros de grupos insurgentes de las minorías étnicas que no hayan firmado una tregua con Rangún y a los miembros de grupos opositores en el exilio como la All Burma Students Democratic Front.

${ }^{25}$ Véase www.iom.int/jahia/Jahia/myanmar.

26 "Preliminary Analisis of Myanmar's 2010 Electoral Laws" por Richard Horsey, Conflict Prevention and Peace Forum, marzo de 2010.

27 "Myanmar's 2010 elections: a human rights perspective" por Benjamin Zawacki, openDemocracy, 30 de Julio de 2010
} 
Philip J. Crowley, dijo que la Ley "se burla del proceso democrático y asegura que las próximas elecciones carecerán de credibilidad. ${ }^{28, "}$

Los recelos sobre la libertad de las elecciones que pudiera despertar la Ley sobre el Registro de Partidos Políticos, se ven amplificados por la lectura de la Ley de la Comisión Electoral de la Unión. Dicha Ley establece que será la Junta militar quien designe a los miembros de la Comisión Electoral y dota a ésta de amplios poderes: delimitación de las circunscripciones electorales; establecimiento de las listas de votantes; capacidad de postponer o suspender las elecciones en un distrito por razón de desastre natural o de inseguridad; establecimiento de tribunales electorales para que juzguen las reclamaciones que se produzcan. Las decisiones de la Comisión Electoral sobre disputas electorales que se produzcan son finales e inapelables. Más preocupante todavía es el punto k del art. 8 que la faculta para "supervisar, ordenar la supervisión y guiar a los partidos políticos para que conduzcan sus actividades conforme a la Ley."

El marco legislativo analizado no permite albergar muchas esperanzas de que el proceso de transición birmano vaya a desembocar en una democracia genuina. Aun así hay autores como Richard Horsey que tratan de ver el vaso medio lleno, a pesar de que apenas tiene gotas de agua: "Estas elecciones, aunque no serán libres y justas, sin embargo representan el cambio político más importante en una generación. Se creará un nuevo espacio político- por constreñido que esté- junto con una clase nueva de instituciones estatales. El envejecido liderazgo militar entregará las riendas del poder a una nueva generación. ${ }^{29, "}$ El International Crisis Group concurre con Horsey en que tal vez se haya abierto una ventana de oportunidad como no se había abierto en 20 años: "Con el General Than Shwe entretando el poder a una nueva generación de líderes, hay una ventana para influir sobre la futura dirección del país. ${ }^{30, "}$

Aunque lo habitual es que el analista de la cuestión birmana acabe cayendo en el escepticismo, merece la pena terminar este artículo considerando si los resultados de las elecciones de noviembre de 2010 y la puesta en marcha de las nuevas instituciones, permiten albergar la esperanza de que el cambio político al que alude Horsey, por más que sea cosmético, puede terminar adquiriendo vida propia y romper el corsé estrecho que le han diseñado los militares.

La campaña electoral de 2010 fue aún menos libre e imparcial que la de las elecciones de 1990 que dieron una abrumadora e inesperada victoria a la Liga Nacional por la Democracia de Aung San Suu Kyi. Aparentemente, esta vez la Junta militar estaba decidida a no dejarse sorprender. En una rueda de prensa concedida el 20 de octubre, el Relator Especial de NNUU para los Derechos Humanos en Birmania, Tomás Ojea Quintana, afirmó que "las condiciones no muestran que las elecciones vayan a ser incluyentes, libres e imparciales. El potencial para que estas elecciones traigan un cambio significativo y una mejora en la situación de los derechos humanos en Myanmar sigue siendo dudoso 31 ". Al día siguiente de las elecciones, el Secretario General de NNUU, Ban Ki-Moon, declaró que las condiciones en las que se habían desarrollado no habían sido lo suficientemente "incluyentes, participativas y transparentes " 32 . El Presidente Obama en un discurso ante el Parlamento indio ese mismo día dijo que las elecciones no habían sido libres ni imparciales y acusó al régimen militar de

\footnotetext{
${ }^{28}$ Agence France Presse, 10 de marzo de 2010.

29 "Preliminary Analysis of Myanmar's 2010 Electoral Laws" por Richard Horsey.

30 "Myanmar's post-election landscape", International Crisis Group, marzo de 2011.

${ }^{31}$ The New York Times, 21 de octubre de 2010.

${ }^{32}$ BBC News, 8 de noviembre de 2010.
} 
haber "robado" las elecciones ${ }^{33}$. Incluso alguien tan patentemente optimista como Richard Horsey se vio obligado a reconocer que "la votación tuvo lugar en una atmósfera pacifica y algo apagada, pero se vio teñida por lo que parece ser una manipulación masiva del voto. ${ }^{34, "}$

A las elecciones concurrieron 40 partidos, que cabría clasificar en tres categorías: 1) El oficialista Union Solidarity and Development Party, que se benefició de los medios del movimiento de masas creado por el régimen, la Union Solidarity and Development Association $^{35}$; 2) Los partidos pro-democráticos, tales como 888 Generation Student Youth o la National Democratic Force, compuesto por ex-miembros de la NLD discrepantes de la decisión de su liderazgo de no concurrir a las elecciones. Estos partidos acusaron la escasez de medios y la dificultad de darse a conocer a los electores; 3) Los partidos de las minorías étnicas, que en general pueden considerarse cercanos a los postulados ideológicos de los partidos pro-democráticos. Obtuvieron resultados algo mejores que los anteriores, sobre todo en las elecciones regionales, como era de esperar dado su mayor arraigo. Fuera de esta tipología queda el National Union Party (NUP), que resulta inclasificable. El NUP fue el partido que el régimen militar formó en 1990 para concurrir a las elecciones y que fue duramente derrotado por la NLD. Sigue abogando por la vía birmana hacia el socialismo, la ideología oficial de la desprestigiada dictadura de Ne Win. Existe la duda de si acabará integrándose en la USDP o si tratará de establecer una tercera vía entre los partidarios del régimen y los más moderados de entre los partidos pro-democráticos ${ }^{36}$.

\section{Tras las elecciones}

Los resultados oficiales de las elecciones fueron anunciados el 18 de noviembre. El oficialista Union Solidarity and Development Party conquistó 259 escaños de los 326 escaños que se disputaban en la Asamblea de los Pueblos y 129 de los 168 en la Asamblea Nacional, así como 496 de los 662 disputados en las Asambleas regionales y estatales. A título de comparación, el segundo partido más votado, el National Unity Party, obtuvo respectivamente 12, 5 y 46 escaños; y el tercero, el Shan Nationalities Democratic Party, 18, 3 y 36. En la composición final de la Asamblea del Pueblo, el USDP controla el 59\% de los escaños, lo que sumado al $25 \%$ de puestos reservados al Ejército, da al régimen control sobre casi el $85 \%$ de los escaños de la cámara. Prácticamente las mismas cifras se repiten en la Asamblea Nacional $(58$ y $25 \%)$.

Estas mayorías tan abultadas colocan en manos de la USDP los siguientes poderes: 1) Poder designar a dos de los componentes de la terna (el tercero lo elegirán los militares) que se somete al colegio electoral presidencial para que elija al Presidente de la Unión. Dada la mayoría que tiene la USDP en ambas cámaras, la designación del Presidente le corresponde

\footnotetext{
${ }^{33}$ Voice of America News, 8 de noviembre de 2010.

34 "Outcome of the Myanmar elections", por Richard Horsey, 17 de noviembre de 2010

${ }^{35}$ El USDP fue creado en marzo de 2010 y fue visto desde el primer momento por los observadores como el sucesor de la Union Solidarity and Development Association, movimiento de masas fomentado por el régimen militar, que lo creó en 1993. Siempre sospecharon los analistas que cualquier transición hacia un gobierno civil se haría por el intermedio de la USDA. El USDP fue fundado por el entonces Primer Ministro de Birmania, Thein Sein, y contaba entre sus miembros a otros prohombres del régimen como el Ministro de Agricultura e Irrigación, Htay Oo, o el Primer Secretario del State Peace and Development Council (nombre oficial de la Junta militar) Thiha Thura Aung Mynt Oo.

${ }^{36}$ Aunque solo haya obtenido el 5\% de los escaños, logró el 23\% de los votos, un porcentaje similar al que había obtenido en 1990. Sorprende un porcentaje tan grande de votos, cuando no era el partido promovido por el régimen, ni el partido del movimiento pro-democrático.
} 
en la práctica; 2) En conjunción con los parlamentarios militares, puede enmendar la Constitución. Por otra parte, el hecho de que los demás partidos juntos no lleguen al $25 \%$ de los escaños de la cámara, les impide: 1) Bloquear las enmiendas constitucionales; 2) Iniciar el proceso de destitución del Presidente; 3) Bloquear el proceso de destitución del Presidente; 4) Convocar una sesión especial de las cámaras.

El 31 de enero de 2011, casi tres meses después de las elecciones y dos meses y medio después del anuncio de los resultados oficiales, se reunió el Parlamento por primera vez. La demora en su convocatoria es sintomática de la importancia que se le atribuye. Otro indicio de lo que se espera de él, son los primeros nombramientos que ha realizado:

- Para el puesto de portavoz de la Asamblea Nacional fue elegido el anterior número tres de la Junta militar, el General Thura Shwe Man y para la Asamblea de los Pueblos el Ministro de Cultura Khin Aung Myint.

- La terna de candidatos a la Presidencia, que escogió el Parlamento, estaba compuesta por el Primer Ministro y presidente del USDP, Thein Sein, el miembro del USDP perteneciente a la minoría shan, Sai Muak $\mathrm{Khan}^{37}$, y el Primer secretario en la Junta militar, Tin Aung Myint Oo. El Colegio Presidencial eligió a Thein Sein como Presidente.

\section{Conclusión}

La impresión es que con 20 años de retraso el régimen militar ha conseguido el objetivo que buscaba en 1990: la "civilización" del régimen y la adopción de los elementos tradicionales de una democracia (Constitución, Parlamento, elecciones), mientras que los militares mantienen el poder, aunque de una manera menos ostensible que en el pasado. Es pronto para decir si se generarán derivas que no estaban previstas en el guión original que acaben llevando al país por sendas inesperadas. No es imposible, pero resulta difícil, dado el grado de control de la situación y de los tiempos y la cohesión que han demostrado los generales que dirigen el país.

\footnotetext{
${ }^{37}$ Sai Muak Khan es un medico sin experiencia política. Su nombramiento hay que verlo como un guiño meramente simbólico a las minorías étnicas.
} 